\title{
Psychological aspects of temporomandibular disorder patients: evaluations after acupuncture treatment*
}

\author{
Aspectos psicológicos de pacientes com disfunção temporomandibular: avaliações pós- \\ tratamento com acupuntura
}

Cassia Maria Grillo¹, Giancarlo de La Torre Canales¹, Ronaldo Seichi Wada¹, Célia Marisa Rizzatti Barbosa ${ }^{1}$, Fausto Berzin¹, Maria da Luz Rosário de Sousa ${ }^{1}$

${ }^{*}$ Received from School of Dentistry of Piracicaba, University of Campinas, Piracicaba, SP, Brazil.

DOI 10.5935/1806-0013.20150022

\section{ABSTRACT}

BACKGROUND AND OBJECTIVES: Depression and somatization are emotional features present in chronic temporomandibular disorder pain patients. This study aimed at evaluating results after acupuncture on psychological aspects of females with chronic muscle temporomandibular disorder pain.

METHODS: Sample was made up of 40 females, aged between 18 and 45 years, submitted to two procedures: acupuncture and splint. Patients were evaluated for one month by the Research Diagnostic Criteria for Temporomandibular Disorders questionnaire Axis II before and after treatment. Treatment expectation before treatment was also evaluated by a visual analog scale with verbal anchors: negative expectation and positive expectation.

RESULTS: There has been chronic pain improvement in 53.3\% of acupuncture patients and in $60 \%$ of splint patients. For severe depression, $11.1 \%$ of acupuncture and $50 \%$ of splint patients have improved. Patients with severe somatization had $16.7 \%$ improvement with acupuncture and $44.4 \%$ with splint. There has been negative correlation $(\mathrm{p}<0.05)$ between treatment expectation and somatization (including and excluding pain items) for the acupuncture group.

CONCLUSION: Both groups have improved some psychological aspects (depression and somatization) after a short period of treatment.

Keywords:Acupuncture therapy, Chronic pain, Depressive symptoms, Masticatory muscles, Temporomandibular joint.

1. University of Campinas, School of Dentistry of Piracicaba, Piracicaba, SP, Brazil.

Submitted in November 17, 2014.

Accepted for publication in May 11, 2015.

Conflict of interests: none - Sponsoring sources: none.

Correspondence to:

Cassia Maria Grillo

Av. Limeira, 901, Areão

13414-903 Piracicaba, SP, Brasil.

E-mail: gricag@hotmail.com

(c) Sociedade Brasileira para o Estudo da Dor

\section{RESUMO}

JUSTIFICATIVA E OBJETIVOS: Depressão e somatização são características emocionais presentes em pacientes com dor crônica de disfunção temporomandibular. O objetivo deste estudo foi avaliar os resultados obtidos após acupuntura nos aspectos psicológicos em mulheres com dor crônica de disfunção temporomandibular muscular.

MÉTODOS: A amostra foi de 40 mulheres, com idades entre 18 e 45 anos, submetidas a dois tratamentos: acupuntura e splint. Foram avaliadas em um período de um mês através do questionário do Eixo II do ResearchDiagnosticCriteria for TemporomandibularDisordersno pré e pós-tratamento. Também se avaliou a expectativa de tratamento no pré-tratamento através de uma escala analógica visual, com as âncoras verbais: expectativa negativa e expectativa positiva.

RESULTADOS: Observou-se melhora no grau de dor crônica em 53,3\% das pacientes da acupuntura e em 60\% do splint. Para depressão grau grave a melhora foi em $11,1 \%$ das pacientes da acupuntura e $50 \%$ do splint. As pacientes com somatização grau grave apresentaram melhora de $16,7 \%$ na acupuntura e $44,4 \%$ no splint. Houve correlação negativa $(\mathrm{p}<0,05)$ entre a expectativa de tratamento e somatização (incluindo e excluindo itens de dor) no grupo acupuntura.

CONCLUSÃO: Em ambos os grupos houve melhora de alguns dos aspectos psicológicos (depressão e somatização) após curto período de tratamento.

Descritores: Articulação temporomandibular, Dor crônica, Músculos mastigatórios, Sintomas depressivos, Terapia por acupuntura.

\section{INTRODUCTION}

The incidence of chronic pain (CP) in the world population varies from 7 to $40 \%$. There is quality of life (QL) impairment which varies from partial to total, permanent or transient disabilities in approximately 50 to $60 \%$ of CP patients ${ }^{1}$. This has major impact on individuals' health, on health services and society and may be difficult to treat ${ }^{2}$.

Most common chronic orofacial pain (OFP) is temporomandibular disorder (TMD) ${ }^{3}$, which encompasses a set of disorders involving masticatory muscles, temporomandibular 
joint (TMJ) and adjacent structures ${ }^{4}$, where there are signs and symptoms such as masticatory muscles and TMD pain, headache, joint noises and limited joint movements, which make difficult activities such as eating, talking, yawning and laughing ${ }^{5}$. Treatment strategies are based on improving symptoms and restoring function and quality of life, with emphasis on reversible therapies ${ }^{5}$, such as physiotherapy, biofeedback, occlusal splints, acupuncture and others ${ }^{6}$.

Its multifactorioal etiology involves several factors affecting the masticatory system and pain perception, either independently or interacting with other causes ${ }^{7}$. Psychological factors may be involved in pain perception, TMD predisposition, onset and perpetuation ${ }^{8,9}$. Depression, anxiety, sleep disorders, somatization and irritability are some emotional features present in chronic TMD patients ${ }^{10}$.

The Research Diagnostic Criteria for Temporomandibular Disorders (RDC / TMD) ${ }^{11}$, the official translation into Portuguese $^{12}$, provides the approach to clinical TMD conditions (Axis I), and Axis II involves pain-related disability and the psychological state, that is, physical diagnosis coordinated with TMD-associated psychosocial stress ${ }^{8}$.

In light of the above, this study aimed at evaluating the effects of acupuncture on psychological aspects of females with TMD-related chronic pain.

\section{METHODS}

This study is part of a larger study carried out in the School of Dentistry of Piracicaba, University of Campinas, Piracicaba, São Paulo (Brazil), between May 2013 and March 2014. For being a study with human beings, it was carried out according to ethical principles and in compliance with the Declaration of Helsinki. All patients have signed the Free and Informed Consent Term (FICT).

Participated in the study 40 females who were recruited by means of ads placed on institution's bulletin board.

Inclusion criteria were females aged between 18 and 45 years, muscle TMD (groups Ia or Ib), according to RDC/TMD ${ }^{11}$, with pain and/or clinical signs and symptoms for more than 3 months. They should also use contraceptives, have no arthritis, diabetes, neurologic diseases or Angle Class I, with all teeth (except $3^{\text {rd }}$ molars).

Exclusion criteria were patients with history of face and TMJ trauma, being submitted to orthodontic treatment, using anti-inflammatory, analgesic and/or myorelaxing drugs, with needle phobia.

Patients were randomly divided in 2 groups: acupuncture $(n=20)$, treated with traditional acupuncture and splint $(n=20)$ treated with stabilizing splint with flat occlusal surface.

Before and after treatment, patients have answered the RDC/ TMD Axis II questionnaire ${ }^{11}$. RDC/TMD Axis II $^{11}$ has specific items to evaluate CP intensity, and depression and somatization scale, which allow the classification in: normal, moderate or severe ${ }^{8}$. CP severity may be evaluated by the Graded Chronic Pain Scale (GCPS), which is made up of six items evaluated in a scale of 10 points and one item regarding the number of disability days due to facial pain ${ }^{13}$. GCPS is specifically directed to pain and functions it prevents to be performed $^{14}$. It allows classifying pain in five levels of chronic pain: 0 (no TMD pain in the last 6 months); I (low disability, low pain intensity); II (low disability, high pain intensity); III (high disability, moderate limitation); IV (high disability, severe limitation $)^{11}$.

To evaluate treatment expectancy, patients were asked before treatment: what is your expectancy with regard to treatment? The answer was evaluated by the visual analog scale (VAS), with verbal anchors: negative expectancy (in the beginning) and positive expectancy (at the end).

The acupuncture group was treated with 4 traditional acupuncture sessions, once a week, lasting 20 minutes. Selected acupoints were: LI4 (Hegu), LI11 (Quchi), SI19 (Tinggong), LR2 (Xingjian), GB20 (Fengchi), GB21(Jianjing), GB34 (Yanglingquan), BL2 (Zanzhu), CV23 (Lianquan) and TE23 (Sizhukong), based on their energetic functions ${ }^{15}$.

Needles were disposable, sterile, individually packed, made of stainless steel of the Huan Qiu brand (Suzhou Huanqiu Acupuncture Medical Appliance Co. Ltd, Suzhou, China), sized $0.22 \times 13 \mathrm{~mm}$ (for facial points insertion) and $0.25 \times 30 \mathrm{~mm}$ (for distal points insertion). Skin was cleaned with cotton and $70 \%$ alcohol. Needles insertion depth and angle were according to the literature ${ }^{15}$. Insertion was unilateral (right side), needles were manually inserted and turned clockwise and anticlockwise until patients reported deqi sensation ${ }^{16}$, described as numbness, pain or heat on needle site or along the meridian ${ }^{17}$.

The splint group was treated with stabilizing splint with flat surface (to be used on the maxillary arch), conventionally manufactured by a single prosthetic technician ${ }^{18}$. As part of this treatment, to make patients aware and educated about their disorder and the importance of using the splint, some information about TMJ, diet (soft diet) and possible parafunctional activities (wide opening yawning, nail biting and others) were given to patients 5 .

Splint was adjusted for adaptation and comfort and was delivered to patients who were oriented to use them only at sleep time. Patients have returned for 4 sessions, once a week, to check and adjust, when needed, occlusal splint contacts. Final evaluation was performed at the end of the 4 sessions.

\section{Statistical analysis}

The statistical analysis was initially used the Shapiro-Wilk test to check the normal distribution of data. $T$ test for paired samples was used for intragroup comparisons and $t$ test for independent samples was used to compare between groups. Pearson correlation was used to check the association between "Treatment expectancy" and depression and somatization scales (nonspecific physical symptoms, including and excluding pain items), during final treatment stage. Significance level was 5\%. The software Bioestat 5.0 was used.

The study was approved by the Research Ethics Committee School of Dentistry of Piracicaba/UNICAMP under protocol 098/2011. 


\section{RESULTS}

Mean patients age was $30.05 \pm 6.59$ years for the acupuncture group, and $30.40 \pm 6.83$ for the splint group. Patients of both groups had pain in the face at least for 6 months, the average pain beginning (in years) $4.82 \pm 3.79$ in the acupuncture group, and $4.05 \pm 5.08$ in the splint group. The pain led to absence from work in both groups (Table 1).

Table 2 shows that before treatment $75 \%$ of acupuncture group patients had CP scale (GCPS) level II (low disability, high pain intensity), the same percentage as the splint group. However, before treatment, $5 \%$ of acupuncture patients had level IV (high disability, severe limitation), and this percent- age was zero after acupuncture. There has been chronic pain improvement after treatment in $53.3 \%$ of acupuncture patients and in $60 \%$ of splint patients.

Before treatment, $45 \%$ of acupuncture patients had severe depression levels, as well as nonspecific physical symptoms (somatization), including pain, where more than half (60\%) had severe pain. The splint group had severe depression level in 30\% of patients, and in nonspecific physical symptoms (somatization), including pain, $45 \%$ of patients had severe level before treatment (Table 2). Improvement in severe depression after treatment was $11.1 \%$ for acupuncture patients and $50 \%$ for splint patients. Patients with severe somatization had $16.7 \%$ improvement with acupuncture and $44.4 \%$ with splint.

Table 1. Descriptive analysis of numerical variables, mean, standard deviation, confidence interval, minimum and maximum values. Piracicaba, 2013/2014

\begin{tabular}{|c|c|c|c|c|c|c|}
\hline & \multicolumn{6}{|c|}{ Confidence Interval (95\%) } \\
\hline & Mean & SD & Upper & Lower & Minimum & Maximum \\
\hline \multicolumn{7}{|l|}{ Age (years) } \\
\hline Acupuncture & 30.05 & $(6.59)$ & 33.13 & 26.97 & 21.00 & 45.00 \\
\hline Splint & 30.40 & $(6.83)$ & 33.60 & 27.20 & 18.00 & 45.00 \\
\hline \multicolumn{7}{|c|}{ Pain onset (years) } \\
\hline Acupuncture & 4.82 & $(3.79)$ & 6.60 & 3.05 & 0.50 & 16.00 \\
\hline \multicolumn{7}{|c|}{ Worst pain (last 6 months) } \\
\hline Acupuncture & 8.20 & $(1.28)$ & 8.80 & 7.60 & 6.00 & 10.00 \\
\hline Splint & 8.10 & $(1.55)$ & 8.83 & 7.37 & 5.00 & 10.00 \\
\hline \multicolumn{7}{|c|}{ Mean pain (last 6 months) } \\
\hline Acupuncture & 6.40 & $(1.96)$ & 7.32 & 5.48 & 2.00 & 9.00 \\
\hline \multicolumn{7}{|c|}{ Treatment expectation (VAS) } \\
\hline Acupuncture & 8.10 & $(1.48)$ & 8.80 & 7.41 & 6.00 & 10.00 \\
\hline Splint & 8,49 & $(1,56)$ & 9,23 & 7,74 & 4,50 & 10,00 \\
\hline
\end{tabular}

VAS = visual analog scale.

Table 2. Distribution of patients according to Research Diagnostic Criteria for Temporomandibular Disorders Axis II variables, as a function of stage and treatment group. Piracicaba, 2013/2014

\begin{tabular}{|c|c|c|c|c|}
\hline \multirow[b]{3}{*}{ RDC/TMD Axis II } & \multicolumn{4}{|c|}{ Groups } \\
\hline & \multicolumn{2}{|c|}{ Acupuncture $(n=20)$} & \multicolumn{2}{|c|}{ Splint $(n=20)$} \\
\hline & Initial (\%) & Final $(\%)$ & Initial (\%) & Final (\%) \\
\hline \multicolumn{5}{|l|}{ Chronic pain scale (GCPS) } \\
\hline 0 (no disability) & 0 & 0 & 0 & 0 \\
\hline I (low disability and low pain intensity) & 10 & 50 & 10 & 60 \\
\hline II (low disability and high pain intensity) & 75 & 35 & 75 & 30 \\
\hline III (high disability, moderate limitation) & 10 & 15 & 15 & 10 \\
\hline IV (high disability, severe limitation) & 5 & 0 & 0 & 0 \\
\hline \multicolumn{5}{|l|}{ Depression } \\
\hline Normal & 30 & 45 & 45 & 50 \\
\hline Moderate & 25 & 15 & 25 & 35 \\
\hline Severe & 45 & 40 & 30 & 15 \\
\hline
\end{tabular}

Continue... 
Table 2. Distribution of patients according to Research Diagnostic Criteria for Temporomandibular Disorders Axis II variables, as a function of stage and treatment group. Piracicaba, 2013/2014 - continuation

\begin{tabular}{|c|c|c|c|c|}
\hline \multirow[b]{3}{*}{ RDC/TMD Axis II } & \multicolumn{4}{|c|}{ Groups } \\
\hline & \multicolumn{2}{|c|}{ Acupuncture $(n=20)$} & \multicolumn{2}{|c|}{ Splint $(n=20)$} \\
\hline & Initial (\%) & Final (\%) & Initial (\%) & Final (\%) \\
\hline Normal & 30 & 40 & 20 & 50 \\
\hline Moderate & 10 & 10 & 35 & 25 \\
\hline Severe & 60 & 50 & 45 & 25 \\
\hline Normal & 45 & 55 & 45 & 65 \\
\hline Moderate & 10 & 10 & 20 & 15 \\
\hline Severe & 45 & 35 & 35 & 20 \\
\hline
\end{tabular}

GCPS = Graded Chronic Pain Scale.

Depression, nonspecific physical symptoms (somatization) including and excluding pain had significantly lower means at the final stage for the splint group (Table 3).

There has been significant negative correlation between treatment expectancy and nonspecific physical symptoms including and excluding pain items, in the final treatment stage for the acupuncture group (Table 4).

Table 3. Mean (standard deviation) of depression and somatization (nonspecific physical symptoms including and excluding pain) variables studied as a function of groups and stages. Piracicaba 2013/2014

\begin{tabular}{llcc}
\hline & & \multicolumn{2}{c}{ Stages } \\
Variables & Groups & Initial & Final \\
\hline Depression & Acupuncture & $1.08(0.74) \mathrm{A}, \mathrm{a}$ & $0.93(0.79) \mathrm{A}, \mathrm{a}$ \\
& Splint & $0.81(0.61) \mathrm{A}, \mathrm{a}$ & $0.60(0.44) \mathrm{B}, \mathrm{a}$ \\
$\begin{array}{l}\text { Nonspecific phy- } \\
\text { sical symptoms } \\
\text { including pain }\end{array}$ & Acupuncture & $1.10(0.77) \mathrm{A}, \mathrm{a}$ & $0.91(0.75) \mathrm{A}, \mathrm{a}$ \\
& Splint & $0.91(0.54) \mathrm{A}, \mathrm{a}$ & $0.62(0.43) \mathrm{B}, \mathrm{a}$ \\
$\begin{array}{l}\text { Nonspecific phy- } \\
\text { sical symptoms } \\
\text { excluding pain }\end{array}$ & Acupuncture & $0.78(0.68) \mathrm{A}, \mathrm{a}$ & $0.61(0.67) \mathrm{A}, \mathrm{a}$ \\
& & & \\
& Splint & $0.70(0.66) \mathrm{A}, \mathrm{a}$ & $0.41(0.50) \mathrm{B}, \mathrm{a}$
\end{tabular}

Means with equal letters horizontally do not differ ( $t$ test for paired samples). Means with equal letters vertically do not differ ( $t$ test for independent samples, $\mathrm{p}<0.05)$.

Table 4. Pearson Correlation Analysis for the "Treatment expectation" variable and depression and somatization scale (nonspecific physical symptoms including and excluding pain), in final treatment stage, according to groups. Piracicaba, 2013/2014

\begin{tabular}{llcc}
\hline Variables & Groups & $\begin{array}{c}\text { Correlation } \\
\text { Coefficient }\end{array}$ & p value \\
\hline Depression & Acupuncture & -0.19 & 0.4101 \\
& Splint & -0.03 & 0.8981 \\
Nonspecific physical & Acupuncture & -0.46 & $0.0388^{*}$ \\
symptoms with pain & Splint & -0.23 & 0.3262 \\
Nonspecific physical & Acupuncture & -0.51 & $0.0198^{*}$ \\
symptoms without pain & Splint & -0.34 & 0.1403 \\
\hline *Statistically significant $(p<0.05)$ & &
\end{tabular}

${ }^{*}$ Statistically significant $(p<0.05)$.

\section{DISCUSSION}

Mean age of patients is that of active adults and pain has caused medical leave, which generates economic costs to society, associated to absence of work and decreased productivity ${ }^{19}$.

Pain is the major reason why patients look for treatment ${ }^{20}$. In chronic TMDs, jaw movement limitations may be persistent or temporary, mild or more severe, but all end up compromising individuals as a whole ${ }^{14}$, negatively affecting their emotional aspects ${ }^{2}$.

This study has observed a considerable number of patients with severe depression ( $45 \%$ in the acupuncture group and $30 \%$ in the splint group) and severe somatization level in $60 \%$ of the acupuncture group and $45 \%$ in the splint group, including pain items. These results are similar to a different study ${ }^{8}$, made up of seven groups of both genders, with different TMD diagnoses obtained as from RDC/TMD Axis I, where approximately $39 \%$ of patients were clinically depressed and 55\% had moderate to severe somatization.

In a multicenter study ${ }^{13}$ (Padua, Tel Aviv and Amsterdam) with TMD patients there has been moderate to severe depression in $52.8 \%$ of the Italian population, in $48.6 \%$ of Israelis and of $37.5 \%$ of Dutch people; moderate to severe somatization in $71.8 \%$ of Italians, $61.8 \%$ of Israelis and $41 \%$ of Dutch. It has to be stressed that participants of the study were patients looking for or being referred by professionals to treatment in specialized centers to treat the disorder, differently from the patients of our study who have come to us to treat chronic facial pain.

Splint group patients have significantly improved after treatment in the items depression and somatization (including and excluding pain). These results were associated to the fact that splint group patients, aiming at making them aware of the TMD problem and the importance of the correct use of the splint, were informed about the disorder, changes in noxious habits and diet, that is behavioral and educational modalities, considered effective tools to control chronic pain, including $\mathrm{TMD}^{2}$.

Statistical analysis has not found significant differences in 
depression and somatization (including and excluding pain) in the acupuncture group, fact which may have occurred due to individual differences, that is, individuals respond differently to acupuncture effects ${ }^{21}$, with different manifestations, which impair the identification of the number of needed acupuncture sessions ${ }^{22}$. According to the literature $^{23}$, acupuncture sessions for chronic pain should initially be performed in alternate days or once a week, in a total of 10 sessions. Another fact which might have influenced these results is that acupuncture group patients had severe depression in $45 \%$ of the sample and severe somatization (including pain) in $60 \%$ of the sample, and in $45 \%$ (excluding pain), and these conditions may influence treatment response, perpetuating a symptom ${ }^{8}$.

It is often proposed that patients' expectancy could be an important factor for the efficacy of acupuncture ${ }^{24}$, that is, patient's expectancy may result in belief and further confidence on treatment ${ }^{25}$, which may shape neuronal activity as if any other specific sensory stimulation were present, resulting in a complex blend of different support physiologies ${ }^{14}$, constituting a secondary effect ${ }^{26}$. Our study has observed in the acupuncture group a negative correlation between treatment expectancy and somatization, that is, the higher the treatment expectancy, the lower the somatization.

The evaluation of psychological factors of TMD patients contributes to predict treatment outcomes ${ }^{13}$ because there are reports of such patients, of numerous and different treatments, most of the times less than satisfactory ${ }^{10}$, so this knowledge may be useful to identify the best treatment to be applied, alone or in association to other treatments, such as cognitivebehavioral therapies.

Limitations of this study were: results cannot be extrapolated to males because we have not evaluated male patients; the lack of a painless control group and the fact that just the splint group has received information about TMD because this was considered treatment standard to make patients aware of the importance of using the splint.

\section{CONCLUSION}

Both groups (acupuncture and splint) have improved some psychological aspects (depression and somatization) after a short period of treatment. For being a chronic pain negatively affecting the emotional aspect, maintaining acupuncture therapy for a longer period could enhance therapeutic benefits.

\section{ACKNOWLEDGMENTS}

To Dr Jorge Eiji Sato for helping in the development of the acupoints protocol.

\section{REFERENCES}

1. Menezes CR, Moreira AC, Brandão WB. Neurophysiologic basis to understand chronic pain through acupuncture. Rev Dor. 2010;11(2):161-8.

2. Campi LB, Camparis CM, Jordani PC, Gonçalves DA. Influence of biopsychosocial approaches and self-care to control chronic pain and temporomandibular disorders. Rev Dor. 2013;14(3):219-22.

3. Jung A, Shin BC, Lee MS, Sim H, Ernst E. Acupuncture for treating temporomandibular joint disorders: a systematic review and meta-analysis of randomized, sham-controlled trials. J Dent. 2011;39(5):341-50.

4. Mobilio N, Casetta I, Cesnik E, Catapano S. Prevalence of self-reported symptoms related to temporomandibular disorders in an Italian population. J Oral Reabil. 2011;38(12):884-90.

5. Alajbeg I. Temporomandibular disorders - the role of neuromuscular dentistry. Med Sci. 2010;34:33-41.

6. Ficnar T, Middelberg C, Rademacher B, Hessling S, Koch R, Figgener L. Evaluation of the effectiveness of a semi-finished occlusal appliance--a randomized, controlled clinical trial. Head Face Med. 2013;9:5.

7. Ohrbach R, Fillingim RB, Mulkey F, Gonzalez Y, Gordon S, Gremillion H, et al. Clinical findings and pain symptoms as potential risk factors for chronic TMD: descriptive data and empirically identified domains from the OPPERA case-control study. J Pain. 2011;12(11 Suppl):T27-45.

8. Yap AU, Tan KB, Chua EK, Tan HH. Depression and somatization in patients with temporomandibular disorders. J Prosthet Dent. 2002;88(5):479-84.

9. Giannakopoulos NN, Keller L, Rammelsberg P, Kronmüller KT, Schmitter M. Anxiety and depression in patients with chronic temporomandibular pain and in controls. J Dent. 2010;38(5):369-76.

10. Ferreira KD, Guimarães JP, Batista $\mathrm{CH}$, Ferraz Júnior AM, Ferreira LA. Fatores psicológicos relacionados à sintomatologia crônica das desordens temporomandibulares - revisão de literatura. RFO. 2009;14(3):262-7.

11. Dworkin SF, LeResche L. Research diagnostic criteria for temporomandibular disorders: Review, criteria, examinations and specifications, critique. J Craniomandibular Disord. 1992;6(4):301-55.

12. Pereira Jr FJ, Favilla EE, Dworkin S, Huggins K. Critérios de diagnóstico para pesquisa das disfunçóes temporomandibulares (RDC/TMD). J Bras Clin Odontol Integr. 2004;8(47):384-95.

13. Manfredini D, Winocur E, Ahlberg J, Guarda-Nardini L, Lobbezoo F. Psychosocia impairment in temporomandibular disorders patients. RDC/TMD axis II findings from a multicentre study. J Dent. 2010;38(10):765-72.

14. Ohrbach R. Disability assessment in temporomandibular disorders and masticatory system rehabilitation. J Oral Rehabil. 2010;37(6):452-80.

15. Lian YL, Chen CY, Hammes M, Kolster BC. Atlas gráfico de acupunctura - Um manual ilustrado dos pontos de acupunctura. Slovenia: H.F.Ullmann; 2005. 238-40p.

16. Kang KW, Kim WY, Kim TH, Shin BC, Jung SY, Kim AR, et al. Adjacent, distal, or combination of point-selective effects of acupuncture on temporomandibular joint disorders: A randomized, single-blind, assessor-blind controlled trial. Integr Med Res. 2012;1(1):36-40.

17. Vanderploeg K, Yi X. Acupuncture in modern society. J Acupunct Meridian Stud. 2009;2(1):26-33.

18. Landulpho AB, Silva WA, Silva FA. Análise dos ruídos articulares em pacientes com disfunção temporomandibular tratados com aparelhos interoclusais. JBA. 2003;3(10):112-7.

19. Macfarlane TV, Blinkhorn AS, Davies RM, Kincey J, Worthington HV. Oro-facial pain in the community: prevalence and associated impact. Community Dent Oral Epidemiol. 2002;30(1):52-60.

20. Tjakkes GH, Reinders JJ, Tenvergert EM, Stegenga B. TMD pain: the effect on health related quality of life and the influence of pain duration. Health Qual Life Outcomes. 2010;8:46

21. Hu WL, Chang CH, Hung YC, Shieh TY. Acupuncture anesthesia for complicated dental extractions in patients with lidocaine allergy. J Altern Complement Med. 2009;15(11):1149-52.

22. Mangal B, Sugandhi A, Kumathalli KI, Sridhar R. Alternative medicine in periodontal therapy--a review. J Acupunct Meridian Stud. 2012;5(2):51-6.

23. Pai HJ, Dias MH, Hosomi JK, Andrade MP. Basic principles and current aspects in the clinical practice of acupuncture. Rev Dor. 2006;7(2):774-84.

24. Colagiuri B, Smith CA. A systematic review of the effect of expectancy on treatment responses to acupuncture. Evid Based Complement Alternat Med. 2012:2012:857804.

25. Liu T. Role of acupuncturists in acupuncture treatment. Evid Based Complement Alternat Med. 2007;4(1):3-6.

26. Pariente J, White P, Frackowiak RS, Lewith G. Expectancy and belief modulate the neuronal substrates of pain treated by acupuncture. Neuroimage. 2005;25(4):1161-7. 